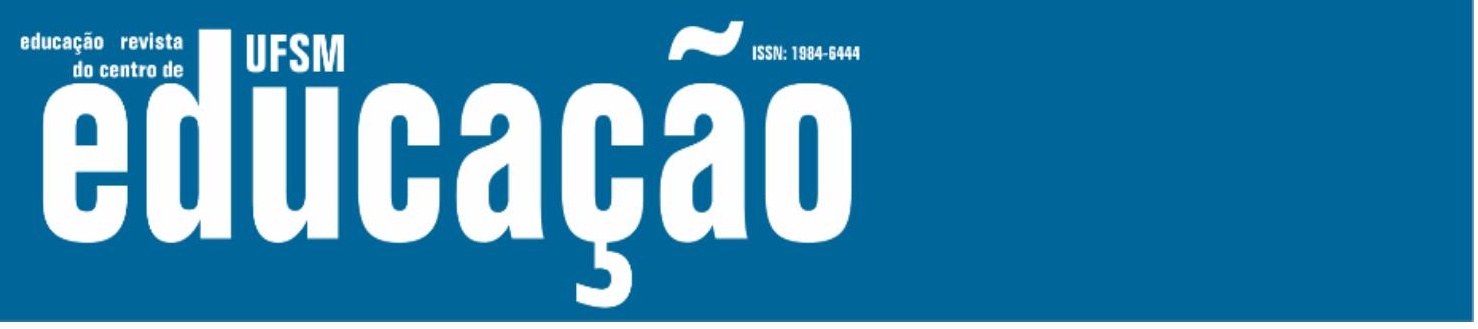

ISSN: 1984-6444 | http://dx.doi.org/10.5902/1984644443534

\title{
Uma análise da implementação do contraturno nas escolas municipais de Belo Horizonte
}

\author{
An analysis of the implementation of daylight hours in municipal schools \\ in Belo Horizonte
}

Marcília de Sousa Silva

Professora Adjunta na Universidade Federal de Viçosa, Campus Florestal, Minas Gerais, Brasil. marcilia.silva@ufv.br - http://orcid.org/0000-0002-6569-4141

\section{Luciana Assis Costa}

Professora Adjunta na Universidade Federal de Minas Gerais, Belo Horizonte, Minas Gerais, Brasil. lucianaassis.ufmg@gmail.com - http://orcid.org/0000-0003-3664-4839

Hélder Ferreira Isayama

Professor Titular Universidade Federal de Minas Gerais, Belo Horizonte, Minas Gerais, Brasil.

helderisayama@yahoo.com.br - http://orcid.org/0000-0002-4442-5356

Recebido em 14 de abril de 2020

Aprovado em 15 de dezembro de 2020

Publicado em 04 de novembro de 2021

\section{RESUMO}

Os programas de contraturno desenvolvidos nas escolas municipais de Belo Horizonte/MG, mais especificamente, os Programas Escola Integrada e Segundo Tempo interagem com a dinâmica escolar e, por vezes, provocam justaposição na concretização de suas ações. O objetivo deste estudo, foi analisar a implementação do contraturno escolar por meio dos discursos dos sujeitos envolvidos no contexto da prática das ações educativas. A investigação contemplou a pesquisa bibliográfica e estudo de caso. Além disso, a técnica de coleta foi a entrevista com coordenadores dos programas, pais, estudantes e educadores e, por fim, a pesquisa baseou-se no ciclo de política e estudos do discurso para refletir as práticas políticas e sociais desenroladas na dinâmica escolar. $\mathrm{Na}$ análise da implementação, os vínculos profissionais podem oferecer fragilidades na efetivação da política, bem como provocar tensões no universo da gestão local e central dos programas que estruturam o contraturno escolar. Ademais, as concepções dos sujeitos envolvidos impactam nos resultados da política. Nesse sentido, esse estudo contribui para as possibilidades de abertura de interpretações dos diversos sujeitos que participam da comunidade escolar, oportunizando a autoria das vozes e protagonismo coletivo no caminho da construção de "encontros potentes".

Palavras-chave: Programa de contraturno escolar; Implementação; Discurso 


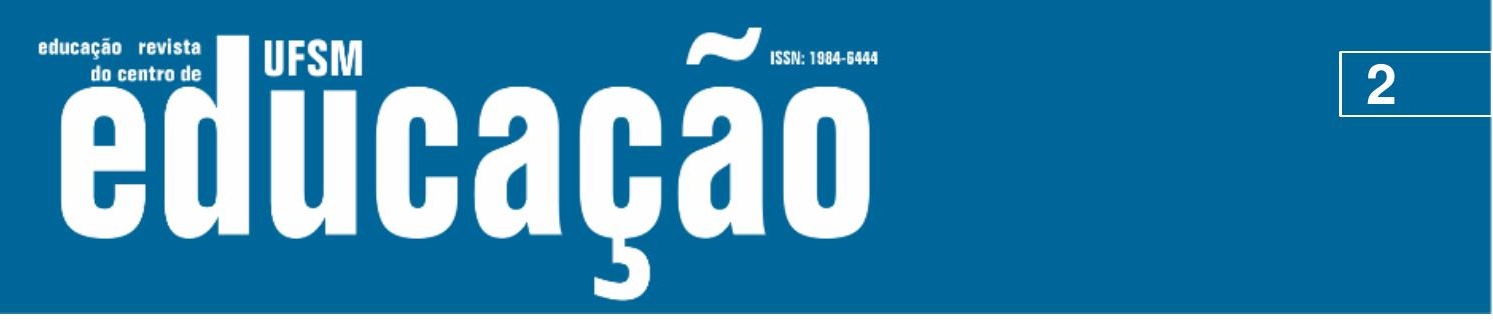

ISSN: 1984-6444 | http://dx.doi.org/10.5902/1984644443534

\section{ABSTRACT}

The evening programs developed in the municipal schools of Belo Horizonte / MG, more specifically, the Integrated School and Second Time Programs interact with the school dynamics and, sometimes, cause juxtaposition in the concretization of their actions. The aim of this study was to analyze the implementation of school hours through the speeches of the subjects involved in the context of the practice of educational actions. The investigation included bibliographic research and case study and, in addiction,the collection technique was the interview with program coordinators, parents, students and educators. Finally, the research was based on the policy cycle and discourse studies to reflect the political and social practices developed in the school dynamics. In the analysis of the implementation, professional ties can offer weaknesses in the effectiveness of the policy as well as cause tensions in the universe of local and central management of the programs that structure school hours. Furthermore, the conceptions of the subjects involved impact the policy results. In this sense, this study contributes to the possibilities of opening interpretations of the various subjects who participate in the school community, providing opportunities for the authorship of voices and collective protagonism in the path of building "powerful encounters".

Keywords: School shift program; Implementation; Discourse

\section{Introdução}

No cenário brasileiro atual, a política educacional que trata da avaliação e temas dos programas da Educação Integral se constitui como agenda da Secretaria de Educação Básica (SEB), cuja Diretoria de Políticas e Regulação da Educação Básica é o setor responsável por essa gestão. Porém, desde os meados dos anos de 2007, o debate sobre a ampliação da jornada escolar e constituição de uma escola brasileira em tempo integral, encontrou um contexto político favorável com a instituição da Diretoria de Educação Integral, Direitos Humanos e Cidadania (DEIDHUC) vinculada à Secretaria de Educação Continuada, Alfabetização e Diversidade do Ministério da Educação (SECAD/MEC) (MOLL, 2011). A partir desse contexto, as intervenções do Ministério da Educação (MEC) passaram a ser orientadas para o aumento da jornada de permanência do estudante na escola e para o desenvolvimento de atividades culturais, esportivas e de lazer que são operacionalizadas por programas de financiamentos. 


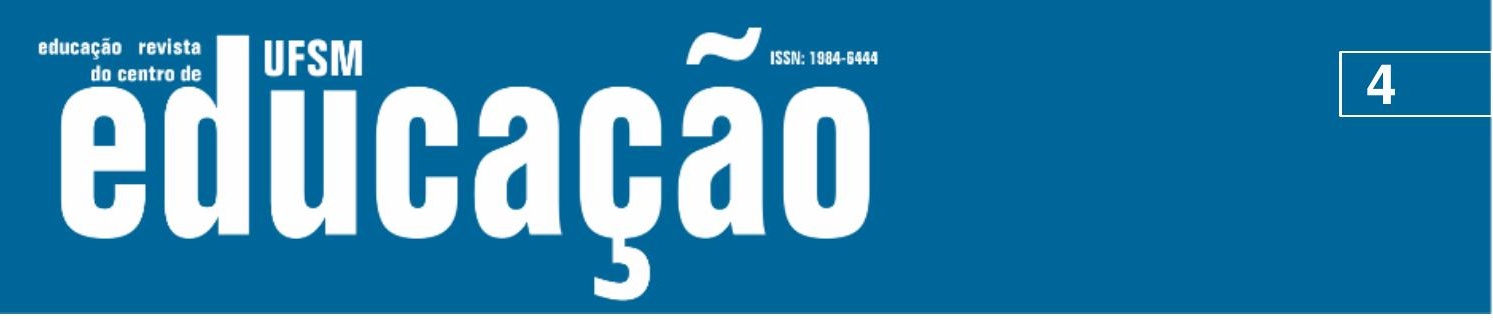

ISSN: 1984-6444 | http://dx.doi.org/10.5902/1984644443534

participantes do Programa Mais Educação desenvolvessem, também, o Programa Segundo Tempo (PST) do Ministério do Esporte. Segundo Mattos e Perim (2012), essa parceria ministerial foi importante tanto pela crença de que a instituição escolar favorece os processos de democratização e acesso ao esporte, quanto contribuiu para que os recursos financeiros chegassem direto na escola.

Com isso, em 2009, o contraturno das escolas municipais de Belo Horizonte passou a se estruturar a partir de dois programas, o PEI e o PST. O primeiro, desenvolvendo ações educativas baseadas nos macrocampos do PME definidos como Acompanhamento Pedagógico, Meio Ambiente, Esporte e Lazer, Direitos Humanos na Educação, Cultura e Artes, Inclusão Digital, Prevenção e Promoção da Saúde, Educomunicação, Educação Científica, Educação Econômica e Cidadania (MINISTÉRIO DA EDUCAÇÃO, 2009). E, o segundo a partir da articulação com o macrocampo Esporte e Lazer. Cabe ressaltar que em 2016 foi instituído o Programa Novo Mais Educação por meio da Portaria nº 1.144/2016 do Ministério da Educação, com o objetivo de priorizar o ensino da matemática e língua portuguesa no contraturno em detrimento do tempo dedicado às outras práticas. Esse programa induz, em tempos atuais, a continuidade do PEI nas escolas de Belo Horizonte.

Por conseguinte, o PST se articulava ao macrocampo Esporte e Lazer possibilitando seu desenvolvimento no formato das oficinas de esportes do PEI. No caso estudado, as oficinas de esportes aconteciam nos moldes do PST e, também, pela ação de monitor vinculado ao PEl. Tais ações tinham contornos pedagógicos diferenciados visto que o primeiro se definia pelo esporte educacional e o outro, esporte participação. Essa articulação dos programas em Belo Horizonte permaneceu até meados de 2016 com a finalização do convênio entre a prefeitura e o Ministério do Esporte'.

Em seus propósitos, os programas PEI e PST anunciavam a melhoria da qualidade da educação na expectativa de desenvolvimento de uma formação integral. Entretanto, cada um desses programas possuía formas diferenciadas de gestão e execução na medida em que se vinculavam a diferentes secretarias municipais e estruturas organizacionais. A implementação desses programas articulou ações das 


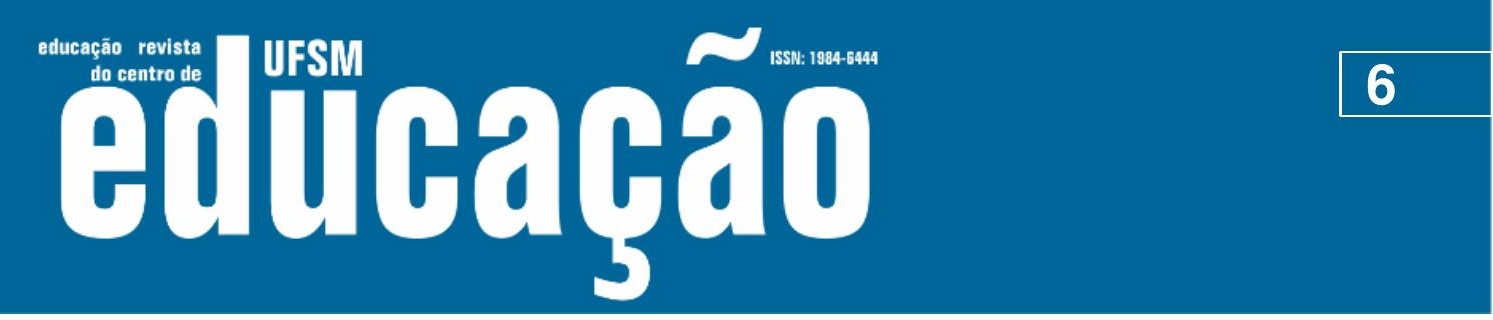

ISSN: 1984-6444 | http://dx.doi.org/10.5902/1984644443534

dessas ações para o desenvolvimento de intervenções compensatórias e de discriminação positiva. A apropriação dessa lógica pelas políticas educacionais resultou numa limitação à inserção no mercado de trabalho, sem ainda provocar profundas transformações necessárias às questões da desigualdade de acesso a bens culturais e econômicos da sociedade contemporânea (FERREIRA e POCHMANN, 2011).

Essas lógicas perpassam a esfera escolar, criam papéis e, muitas vezes, condicionam as práticas sendo reforçados numa perspectiva acrítica e funcionalistas. Compreendemos que os contextos que constituem o ciclo de políticas são marcados pela ideia de representação, ainda que os textos políticos sejam a representação da política, eles serão 'lidos' a partir das demandas do contexto da prática onde as consequências são experimentadas. Desse modo, acreditamos na importância de desvelar os discursos que constituem os projetos educacionais para que os sujeitos que neles se envolvem tenham condições de participar das 'lutas' desse campo.

Parafraseando Silva (2011), os sujeitos da educação são atores que compõem as arenas de luta das políticas educacionais e, pensamos que necessitam adentrar nesse campo de debate de projetos em disputa. Os discursos em cena podem sustentar ou privilegiar determinadas concepções e práticas organizacionais e provocar estagnações, retrocessos ou transformações no desenvolvimento da educação. Portanto, nosso objetivo é analisar a implementação por meio dos discursos dos sujeitos envolvidos no contexto da prática das ações educativas. Compreendemos, assim, que no processo de implementação devemos levar em conta o contexto da prática no qual o papel e influência dos burocratas podem alterar os rumos e resultados das políticas públicas (LOTTA, 2012).

\section{O contraturno das escolas municipais belorizontinas}

Na dinâmica das escolas municipais, houve uma aproximação dos programas de PEI e PST e, por vezes, uma justaposição na concretização das ações do contraturno escolar. A sobreposição de ação também é refletida no nível da gestão, visto que seus coordenadores centrados em suas respectivas secretarias, SMEL e 


\section{Uism Autoabat

ISSN: 1984-6444 | http://dx.doi.org/10.5902/1984644443534

estratégias de correção de fluxo, bem como investe em mecanismos de permanência e garantia de acesso à educação. O contraturno escolar é o resultado de uma dessas medidas que, no caso das escolas municipais de Belo Horizonte, a implementação da jornada escolar ampliada conta, ainda, com articulações de outros setores da gestão pública e da sociedade.

Para efetivar tais ações, o Programa articula investimentos oriundos de três esferas governamentais, dos órgãos da Prefeitura de Belo Horizonte, das escolas municipais e de demais instituições, como instituições de Ensino Superior, instituições do Terceiro Setor, clubes recreativos e esportivos, empresas privadas, museus e igrejas, dentre outras (SMED, 2015, p.24).

O sentido da implementação exige compreender os processos de produção da política, os quais compreendemos a partir dos contextos que influenciam e das práticas e interações dos sujeitos participantes das ações. Dessa forma, tratar da implementação de programas de contraturno é exigir mais do que colocar em funcionamento. Charaudeau (2014) estabelece que o significado de uma palavra, texto ou conversa se refere ao discurso e a necessidade de contextualização e é nessa perspectiva que buscamos o sentido da implementação. Essa premissa nos permite compreender a implementação como produto do ciclo da política e, portanto, constituída também da execução.

Entendemos que a implementação de políticas públicas é um processo complexo, cuja ampliação de análise deve considerar as agências, instituições, o contexto e sujeitos envolvidos. Considerando esses últimos, interpretamos que a implementação é definida pela "interação entre atores no interior dos ambientes institucionais e relacionais presentes nas comunidades políticas" (LOTTA, 2008, p. 4). Corroboramos com Lotta (2008) que as dinâmicas políticas são resultado dessas interações, ou seja, a implementação é um processo com envolvimento de um sistema e as políticas são implementadas "pela burocracia em interação" (p. 4). 


\section{$\sim$ ussm,

ISSN: 1984-6444 | http://dx.doi.org/10.5902/1984644443534

(CO6) reforça o discurso do tempo da escola voltado para o estudo, aqui, percebido, como instrução que é uma função da instituição.

No caso dos sujeitos relacionados com o contexto da prática, é ressaltado a dicotomia que se estabelece entre o tempo da escola e o tempo ampliado do PEI e PST. Os sujeitos da escola utilizam o termo 'escola regular' para dizer de um momento da dinâmica escolar que tem se configurado como uma 'outra escola'.

Muitas vezes, o aluno que dá trabalho na escola regular não tem problema na Escola Integrada (EM3).

A escola regular tem desenvolvido muito o trabalho do esporte proporcionando campeonatos, jogos internos, e isso é bom (EP6).

De tarde tem uma regular e de manhã eu fico na Integrada (E1- 7 anos).

Compartilhamos com Masschelein e Simons (2013) que a escola - tradução mais comum da palavra grega skholé - "oferece tempo livre" (p.9) e transforma o conhecimento e as habilidades em "bens comuns" (p.10). As autoras afirmam que a escola tem a potencialidade de, independentemente de antecedentes, talento ou aptidão, facultar a todos os sujeitos, o tempo e espaço para saírem da cena conhecida e superar e renovar o mundo. E, que, renovar, talvez, seja um dos elementos essenciais da/na escola visto que promove mudanças imprevisíveis (MASSCHELEIN; SIMONS, 2013).

Eu creio que não vamos formar profissionais por meio das oficinas que temos, mas formar cidadãos que saberão conviver em cada lugar, que levará o ensinamento da capoeira para vida, que terá acesso à informática mesmo que não seja um profissional do computador, que terá inteligência para saber o que pode e não pode fazer, que levarão alegria que vivem com os monitores, que levará o que viveu aqui para a vida (EM5).

Compartilhamos dessa lógica na medida em que refletimos sobre a escola pública como 'tempo livre' para experiências de aprendizagens, de (re)conhecimento e de produção de saberes. Os conhecimentos escolares não restringem ao que acontece no interior da escola, ou seja, a vida que corre fora dela deve compor seu currículo. 


\section{Tusm

ISSN: 1984-6444 | http://dx.doi.org/10.5902/1984644443534

Tem três anos que eu estudo na escola e estou na Integrada desde que entrei na escola. Eu penso que a escola é boa, mas o ensinamento aqui não é muito bom. Eu estou no $8^{\circ}$ ano do $3^{\circ}$ ciclo e acho que o ensino pode melhorar (E3 - 13 anos).

A escola, eu valorizo porque é muito boa. Então, eu acho que o ensino é fraco, mas a escola tem cuidado das meninas (CO7).

Considerando as falas acima e seu contexto de produção, inferimos que o discurso da qualificação da escola se dá pelo seu processo de ensino e aprendizagem visto que no campo educacional a 'qualidade da educação', principalmente pública, passa pelos seus resultados valorizados socialmente. Aqui, outras dimensões da educação, como a cultural e política, tornam-se invisíveis.

O relato e os elementos presentes nas falas, nos levam a deduzir que a escola passa a ter uma significação qualificada na medida em que sugerem que não é somente a instrução que faz dela uma instituição boa. Os falantes consideram que outras nuances são importantes na composição das práticas escolares: a atenção e o cuidado. Interpretamos que essa expectativa de 'escola boa' por meio do cuidado e atenção, reforça o consenso de pobreza que engloba os ditos que, de certa forma, organizam as práticas escolares. "Olha, eu penso que a escola é muito boa. Agora, os alunos precisavam dar mais valor porque apesar deles não terem nada, eles estragam a escola" (E3 - 12 anos - grifo nosso). O trecho destacado revela "o cuidado" e pode colocar a escola num patamar de resolução de demandas sociais que vão além dos processos de ensino e de aprendizagens. A instituição é representada a partir de seus efeitos sobre o cuidar e proteger seus estudantes da fome, da 'rua', dos riscos que se apresentam fora dela.

Essas significações compõem o universo da política educacional e necessitam de reflexão no que diz respeito às construções subjetivas sobre qualidade (educacional e ou escolar), articulação, saberes e poderes para entender o grupo social e suas relações com a dimensão da vida. No processo cíclico das políticas constituído por influências, agendas, textos e práticas é relevante o olhar para os implementadores tendo em vista que suas práticas são impactadas pela ação institucional que também é influenciada por meio de decisões tomadas na execução. 


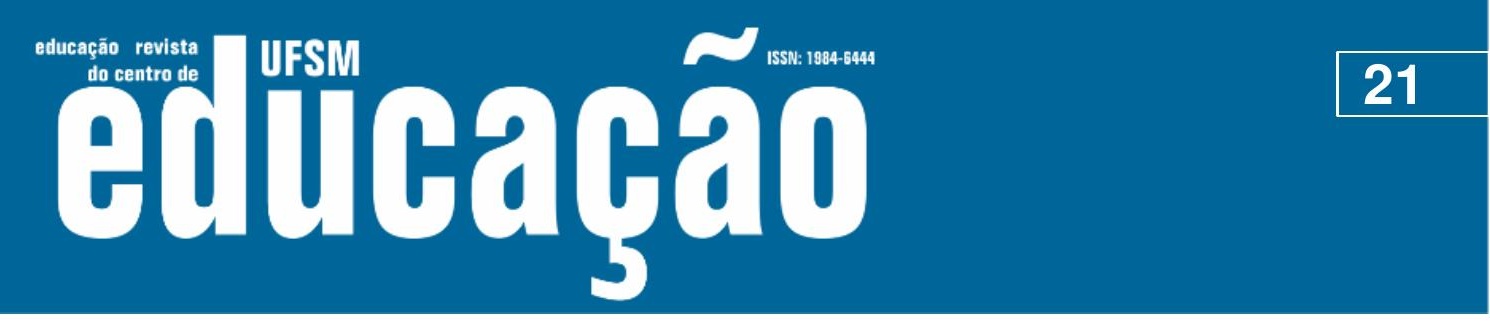

ISSN: 1984-6444 | http://dx.doi.org/10.5902/1984644443534

\section{A implementação do contraturno escolar}

Pensar a implementação dos programas de contraturno escolar remete à discussão sobre como as ações são colocadas em prática e de que forma criam estratégias de intervenção, bem como os impactos do processo na política. Ao tratar de implementação, o olhar se volta para a atuação considerando que suas contingências são explicadas "pelas decisões tomadas por uma cadeia de implementadores no contexto político, institucional e econômico que operam" (LOTTA, 2012, p. 27).

Por vezes, o ciclo da política segue o curso sequencial (top down) e as tomadas de decisão não são (com)partilhadas entre os sujeitos 'da ponta', da execução, dificultando os processos operacionais da implementação.

\footnotetext{
Para além da gestão interna, nós temos as questões de coordenação na escola porque é um choque na organização do trabalho. E as especificidades da diretriz do PST não são vislumbradas na escola, visto que o PST tem uma normativa diferenciada para o quadro de recurso humano do que 0 Programa Escola Integrada. Existe uma organização de tempos do profissional diferenciada, o salário é diferenciado e os processos formativos são específicos o que gera um desconforto dentro de algumas escolas com os monitores e coordenadores do Programa Escola Integrada. Isso não deveria provocar ranços tendo em vista que o PST faz parte da matriz do PEI. O que justifica a inserção do PST no Programa Escola Integrada é o macrocampo Esporte e Lazer (EP5) (Grifos nossos).
}

As expressões grifadas traduzem alguns efeitos de um modelo que estrutura um programa sem considerar as questões de sua gestão no ambiente escolar. A compreensão da escola pública como uma esfera democrática, parte do entendimento de que as questões administrativas e gerenciais são relevantes para criar condições para que todos os agentes que nela atuam tenham condições de exercerem seus papéis políticos e éticos na tarefa de educar. Dessa maneira, o trato da gestão do trabalho deve propiciar formas pelas quais o trabalho docente deve ser pensado $\mathrm{e}$ possibilitar aos trabalhadores oportunidades de formação e valorização das condições do trabalho.

Temos a compreensão de que a implementação dos programas é resultante de variáveis e decisões complexas no âmbito da instituição, e essas se tornam base para 


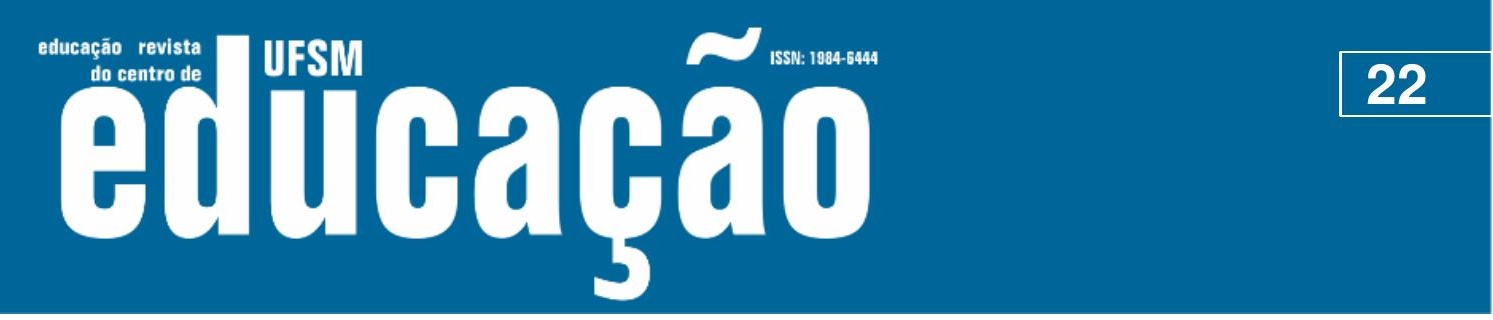

ISSN: 1984-6444 | http://dx.doi.org/10.5902/1984644443534

a ação dos implementadores. A complexidade se define pelas diferentes diretrizes e normas de organização dos programas Escola Integrada e Segundo Tempo, que permite lacunas na interação dos processos de intervenção.

\begin{abstract}
Essa questão de adaptar atividade, modificar uma ação, de alterar o módulo aula, a carga horária de atendimento, adequar o número de monitor ao de estudantes, essa flexibilidade que o Programa Escola Integrada tem, o Segundo Tempo não tem. Ainda hoje existem umas poucas escolas com dificuldades de se adequarem os núcleos à organização do Programa Escola Integrada, mas isso é um processo de construção. Quando tivemos a avaliação do Ministério do Esporte, houve a análise que, muitas vezes, o Segundo Tempo fica à mercê do Programa Escola Integrada, mas para mim isso é uma visão de quem está de fora e que não conhece essa relação, na qual não cabe ser intransigente. É preciso entender que o Programa Escola Integrada tem uma organização e sendo uma parceria, às vezes, nós temos que tentar ajustar da melhor forma possível e sem atropelar (EP4) (Grifos nossos).
\end{abstract}

O encontro dos programas de contraturno escolar com normativas diferenciadas, coordenações distintas e gerenciados por setores diferentes do organismo público no interior da escola, provoca consensos e dissensos a partir das percepções individuais. A fala do educador professor (EP4), indica que o profissional faz uma leitura abrangente em relação ao contexto da escola e as particularidades do Programa Escola Integrada, percebendo a necessidade de ajustamento de 'normas' no sentido de preservar os objetos dos programas sem desqualificá-los. A narrativa expressa que o contexto da prática exige outras configurações dos programas no intuito de possibilitar uma flexibilização na estrutura e organização que não é percebida pelos formuladores dos PST na "visão de quem está de fora e não conhece a relação".

Existem falas dos sujeitos do interior da escola que reforçam a necessidade de diálogo no processo de 'chegada' do PST e do PEI na instituição:

Eu acho que a gente tem muita dificuldade porque as diretrizes são diferentes. As diretrizes não se encontram e tem momentos que parecem várias escolas dentro de uma só. Isso não dá para entender. Eu acho que educação é um projeto só, mas que tem um tanto de outros programas dentro (EM5) (Grifo nosso). 


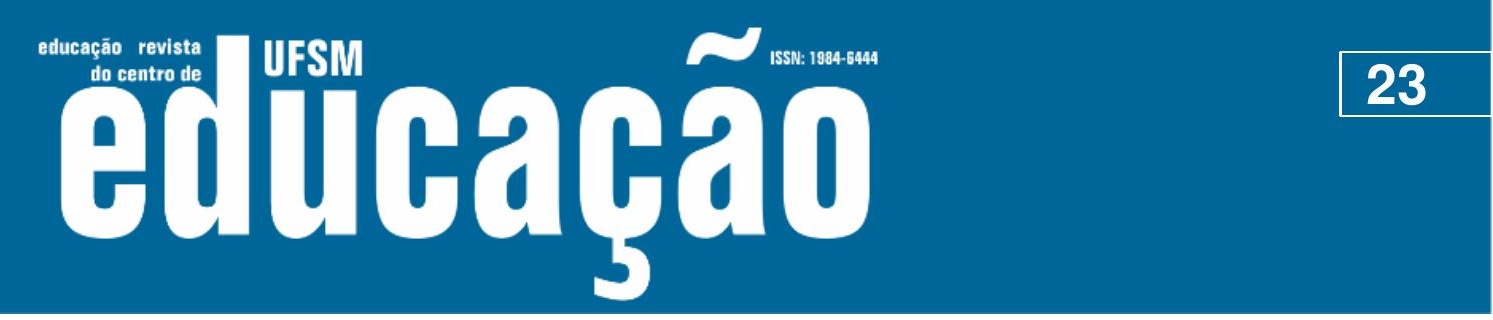

ISSN: 1984-6444 | http://dx.doi.org/10.5902/1984644443534

\begin{abstract}
As diretrizes sendo diferentes não é tão tranquilo para a escola porque a gente não pode perder de vista a essência do PST, mas não pode atropelar a diretriz do Programa Escola Integrada. A gente não pode alterar a normalidade da escola e do PEI. É um pouco complicado, até no relacionamento. Não é fácil, mas não é impossível. Obviamente, que não posso julgar, mas eu observo que, a Escola Integrada em relação a escola regular, existem preconceitos. Os professores, funcionários diferem nas relações com a Escola Integrada. Isso vai afetar as relações entre os programas também porque o pessoal desconhece o Segundo Tempo, a proposta e isso atrapalha um pouco (EP3).
\end{abstract}

A educação pensada como um projeto único da escola, leva a interpretar que os programas de contraturno são percebidos como conjunto de práticas que educam e, por isso, fazem parte de um aparato organizacional, curricular e pedagógico que constrói as formas de produção dos significados. No entanto, Cavaliere (2007) afirma que é possível estabelecer o modelo de aluno em tempo integral, ou seja, uma perspectiva que resulta de práticas diversificadas nos tempos alternativos, possibilitadas por articulações com instituições multissetoriais e pela ação educativa utilizando espaços e agentes que não sejam os da própria escola. Tal modelo difere do que propõe o fortalecimento da unidade escolar e atribuição de novas tarefas e formação diversificada, que oportunizam uma vivência institucional de outra ordem.

Percebemos que a organização do PST na conjuntura escolar se dá de forma diferenciada a partir dos papéis assumidos pelos coordenadores de núcleo. Ora como oficina de esporte pensada na lógica de organização do PEI, e, por vezes, imbuído de normas pouco flexíveis à organização das demais práticas do contraturno. Por meio da observação sistemática, notamos que existe uma autonomia dos núcleos do PST em planejarem suas atividades, independentemente da proposta de ação do PEI. Entretanto, há um tensionamento no que se refere à gestão pedagógica e de pessoas do PST. Outro fator que influencia é a diversidade que compõem os sistemas de pensamentos dos atores da implementação

Tem algumas coisas que são combinadas no nível central e o professor coordenador do Programa Escola Integrada desconhece, como exemplo, a organização de turmas, os tempos formativos do Segundo Tempo. E, mesmo explicando a Escola Integrada pede orientação por escrito da coordenação geral do Segundo Tempo e, muitas vezes, precisa da ação do acompanhante da regional para ajustar (EP4). 


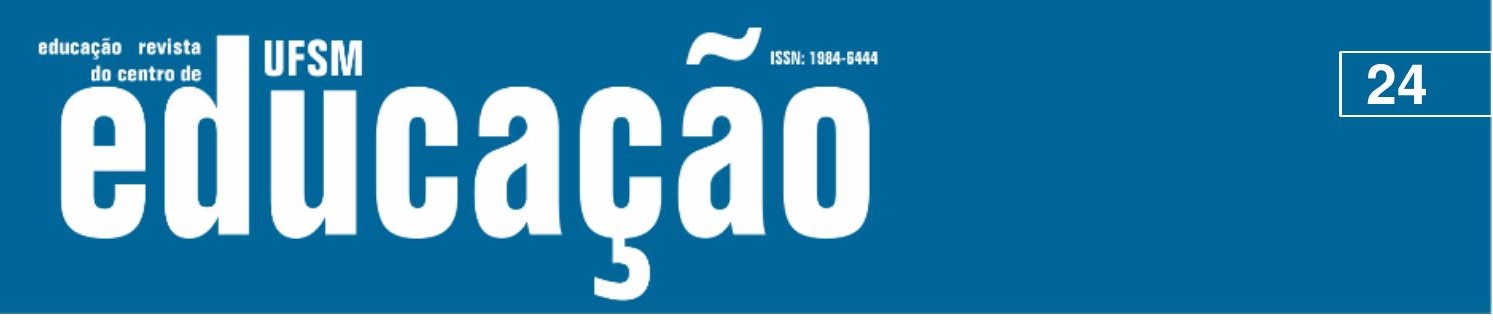

ISSN: 1984-6444 | http://dx.doi.org/10.5902/1984644443534

O Segundo Tempo veio para complementar as atividades da Escola Integrada. Eu acho que a gente precisa entrosar mais com esses programas dentro da escola, apesar de ver que isso depende do perfil do monitor e do professor que está trabalhando (EP6).

A constatação das lacunas existentes na gestão dos programas dentro da escola, provoca pensar que as práticas necessitam de articulação do trabalho dos educadores de forma cooperativa para dar conta das questões do educar que lhes são comuns. É necessário que o contexto educativo tenha uma ampliação do diálogo e organização da dinâmica em prol dos efeitos que se espera da instituição escolar.

\section{Considerações finais}

No estudo da implementação do contraturno escolar, buscamos no Ciclo de Política de Stephen Ball, os contextos de produção dos processos da política para fundamentar a análise no contexto da prática. Esse, entendido como o lugar no qual as políticas são reinterpretadas e, portanto, espaço de potencialização para mudanças no texto original. $\mathrm{Na}$ investigação buscamos entender as práticas discursivas escolares por meio das falas e ações dos sujeitos implementadores que integram a comunidade escolar e assumem papéis diferenciados no contexto de produção do discurso.

O entendimento dos implementadores (educadores monitores e professores) dos programas de contraturno escolar, orientam para a noção de proteção social e cuidado aos estudantes participantes, e de certa forma, às suas famílias. No contexto do entorno escolar, a realidade da ocupação reflete na escola que se tornou um relevante espaço para reflexão e sistematização da vida daquela comunidade. Ao considerar que os programas de contraturno escolar têm um papel prioritário de 'tirar da rua' as crianças e adolescentes moradores do bairro, os sujeitos da educação trazem para o universo da escola uma demanda social que não se soluciona sozinha. A escola passa a assumir para si uma demanda que é de cunho das políticas públicas, como saúde, segurança, esporte, lazer, moradia, emprego. E, com isso, provoca lacunas e insatisfações no que diz respeito aos resultados que se espera dela, 


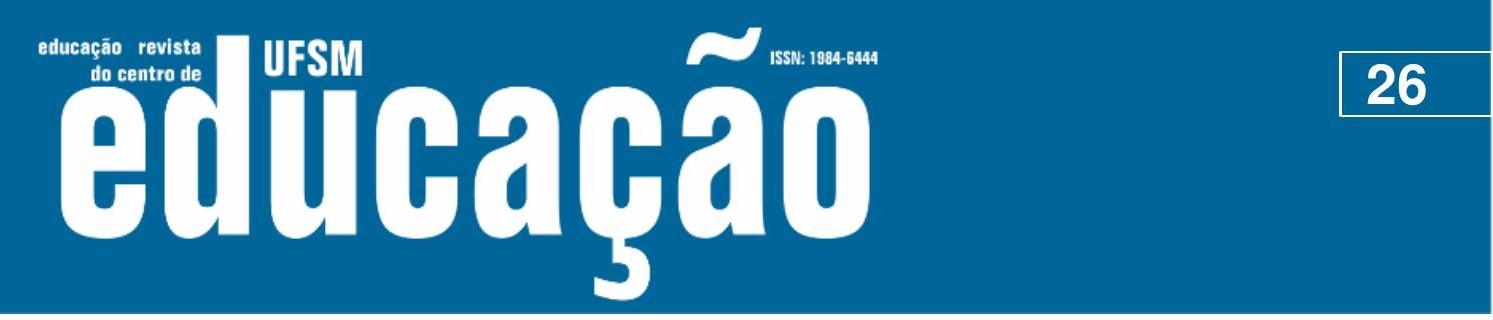

ISSN: 1984-6444 | http://dx.doi.org/10.5902/1984644443534

BALL, Sthefen John. Intelectuais ou técnicos? O papel indispensável da teoria nos estudos educacionais. In: BALL, S.J. Políticas Educacionais questões e dilemas. São Paulo: Cortez, 2011. p.7899.

BALL, Sthefen John; MAINARDES, Jeferson. Políticas educacionais: questões e dilemas. São Paulo, 2011.

BELO HORINTE - DOM. Diário Oficial do Município. 2014 Disponível em: https://domweb.pbh.gov.br/visualizacao/edicao/1201. Acesso em : 02 fev. 2017.

BRASIL. Portaria Normativa Interministerial $n^{\circ}$ 17, de 24 de abril de 2007. Institui - Programa Mais Educação que visa fomentar a educação integral de crianças, adolescentes e jovens, por meio do apoio a atividades socioeducativas no contraturno escolar. Diário Oficial da União, Brasília, DF, 26 abr. 2007.

CANCLINI, Nestor Garcia. Culturas híbridas. Debolsillo, 2013.

CAVALIERE, Ana Maria. Tempo de escola e qualidade na educação pública. Educação \& Sociedade. Campinas, vol. 28, n. 100 - Especial, p. 1015-1035, out. 2007 Disponível em http://www.cedes.unicamp.br

CHARAUDEAU, Patrick. Dicionário de análise do discurso. Contexto, 2014.

DUSO, Ana Paula; SUDBRACK, Edite Maria. Políticas educacionais: textos, contextos e práticas - interfaces possíveis. Vivência. v. 6, n. 11, p. 65-80, out, 2010.

FARIA, Carlos Aurélio Pimenta. Implementação: ainda o "elo perdido" da análise de políticas públicas no Brasil?. Revista Debates, v. 6, n. 2, p. 13, 2012. Dispponível em: https://www.seer.ufrgs.br/debates/article/view/26227. Acesso em 03 fev. 2020. DOI: https://doi.org/10.22456/1982-5269.26227

FERREIRA, Eliza Bartolozzi; POCHMANN, Márcio. Educação e juventude na sociedade pós-industrial. In: DUARTE, Adriana.; OLIVEIRA, Dalila Andrade (orgs) Políticas públicas e educação: regulação e conhecimento. Belo Horizonte: Fino Traço, 2011. p.239-260.

FRIZZO, Giovanni. Crise do capitalismo, política ultraliberal e a extinção do ministério do esporte. Motrivivência, Florianópolis, v. 31, n. 60, p. 01-16, set. 2019. ISSN 21758042. Disponível em: https://periodicos.ufsc.br/index.php/ motrivivencia/article/ view/2175-8042.2019e67108/41115. Acesso em: 06 fev. 2020. doi:https://doi.org/10.5007/2175-8042.2019e67108.

GALLO, Sílvio. Transversalidade e educação: pensando uma educação nãodisciplinar. In: ALVES, Nilda; GARCIA, Regina Leite (org.), 0 sentido da escola. 5. ed. Petrópolis: DP et Alii, 2008. p 15-35. 


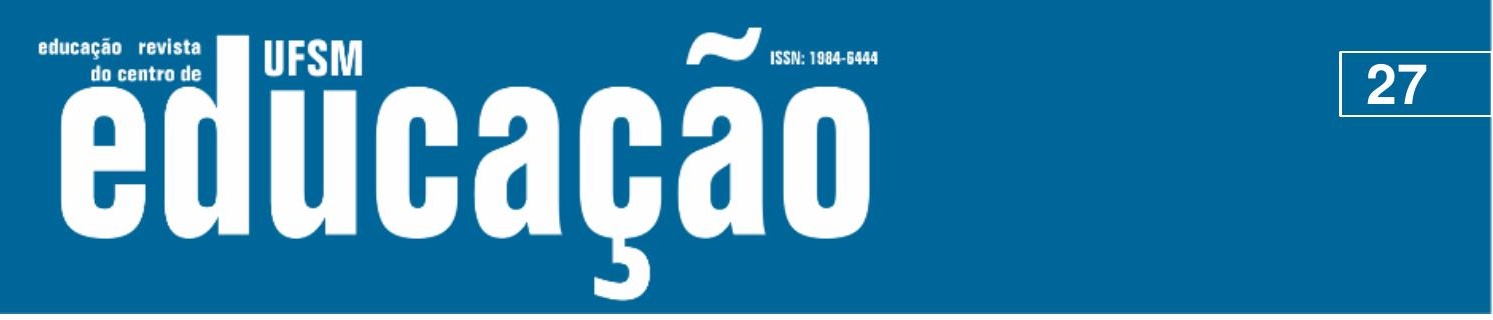

ISSN: 1984-6444 | http://dx.doi.org/10.5902/1984644443534

HANSEN, Fábio Roberto; PERIM, Gianna Lepre.; OLIVEIRA, Amauri Aparecido Bassoli. Apresentação. In: OLIVEIRA, Amauri Aparecido Bassoli.; PERIM, Gianna Lepre. (orgs.) Fundamentos pedagógicos do Programa Segundo Tempo: da reflexão à prática. Paraná: Eduem, 2009, p. 9-18.

KLEIN, Carin; DAMICO, José. O uso da etnografia pós-moderna para a investigação de políticas públicas de inclusão social. In: MEYER, D. E. ; PARAísO, M. A. Metodologias de pesquisas pós-críticas em educação. Belo Horizonte: Mazza Edições, 2012, p.63-85.

LOPES, Alice C.; MACEDO, Elizabeth. Contribuições de Stephen Ball para o estudo de políticas de currículo. In: BALL, S.; MAINARDES, J. (Orgs.). Políticas educacionais: questões e dilemas. São Paulo: Cortez, 2011. p. 249-283.

LOTTA, Gabriella Spanghero. Estilos de Implementação: ampliando o olhar para análise de políticas públicas. ANPAD. Salvador, 2008. Disponível em www.anpad.org.br/diversos/trabalhos/EnAPG/enapg_2008/2008_ENAPG208.pdf.

Acesso em 28 mai.2015.

LOTTA, Gabriella Spanghero. O papel das burocracias do nível da rua na implementação de políticas públicas: entre o controle e a discricionariedade. In: FARIA, A. P. Implementação de políticas públicas: teoria e prática. Belo Horizonte: Ed. PUC Minas, 2012. p. $20-49$.

MAINARDES, Jeferson; FERREIRA, Márcia Santos; TELLO, Cesar. Análise de políticas: fundamentos e principais debates teórico-metodológicos. In: BALL, S.J. Políticas Educacionais questões e dilemas. São Paulo: Cortez, 2011. p.143-169.

MAINGUENEAU, Dominique. Discurso e Análise de discurso. São Paulo: Parábola Editorial, 2015, 192p.

MAINGUENEAU, Dominique. Gênese dos discursos. Parabola, 2008.

MASSCHELEIN, J.; SIMONS, M. Em defesa da escola pública. Belo Horizonte: Autêntica, 2013174p.

MINISTÉRIO DA EDUCAÇÃO. Manual de Educação Integral. Disponível em $\mathrm{ftp}: / / f t p . f n d e . g o v . b r / w e b / p d d e /$ manual_pdde_2009_escola_integral.pdf Acesso em 28 abr. 2011.

MOLL, Jaqueline. Educação Integral no Brasil: itinerários na construção de uma política pública possível In: MOLL, J.(org.) Tendências para a educação integral. São Paulo: Fundação Itaú Social CENPEC, 2011. 


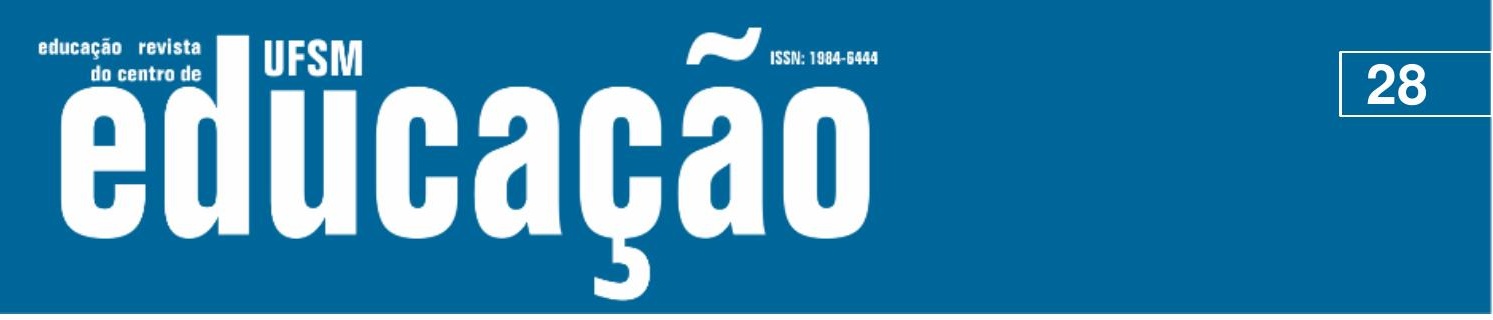

ISSN: 1984-6444 | http://dx.doi.org/10.5902/1984644443534

NEUBAUER, R. Políticas de Educação. In: GIOVANNI, G.; NOGUEIRA, M. A. Dicionário de Políticas Públicas. São Paulo: Editora Unesp, Fundap, 2015, p. 106110.

OLIVEIRA, Adriana F. Políticas Públicas Educacionais: conceito e contextualização numa perspectiva didática. In: OLIVEIRA, A.F. (org.) Fronteiras da Educação: desigualdades, tecnologias e políticas. Goiás: Editora da PUC, 2010. p. 93-99.

PAIVA, Fernanda S. L. de. Escolarização. In: GONZÁLEZ, Fernando Jaime; FENSTERSEIFER, Paulo (org.) Dicionário Crítico de Educação Física . ljuí: Ed. Unijuí, 2008, 2 ed. p.167 - 170.

MATOS, Dirceu; PERIM, Gianna Lepre. Acompanhamento operacional, pedagógico e administrativo dos convênios do Programa Segundo Tempo-a visão da Secretaria Nacional de Esporte Educacional. In: GOELLNER, S. V.; SOARES, L.S.S.;CARVALHO, M.A. A.(orgs). Programa Segundo Tempo: memória, experiências, avaliação e perspectivas no encontro das equipes colaboradoras. Maringá: Eduem, 2012, p. 219-238.

SALGADO, Juarez A. Desigualdade social. In: OLIVEIRA, D.A.; DUARTE, A.M.C. e VIEIRA, L.M.F. (orgs) DICIONÁRIO: trabalho, profissão e condição docente. Belo Horizonte: UFMG/Faculdade de Educação, 2010. CDROM

SÁNCHEZ GAMBOA, Silvio. Pesquisa em educação: métodos e epistemologias. Chapecó: Argos, 2012. 212p.

SAVIANI, Demerval. O Plano de Desenvolvimento da Educação: análise do projeto do MEC. Educação \& Sociedade. Campinas, vol. 28, n. 100. Especial, out, 2007, p.1.231-1.255. Disponível em: http://www.cedes.unicamp.br. Acesso em 28 mai.2015.

SILVA, Tomaz Tadeu. Currículo e Identidade social: territórios contestados. In: SILVA, T.T. (org.) Alienígenas na sala de aula: Uma introdução aos estudos culturais em educação. 9 ed. Petrópolis: Vozes, 2011. p.185-201.

SMED. Educação Integral: Diretrizes Político-Pedagógicas e Operacionais. Belo Horizonte: Secretaria Municipal de Educação/Prefeitura Belo Horizonte, 2015 (impresso).

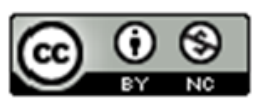

This work is licensed under a Creative Commons Attribution-NonCommercial 4.0 International (CC BY-NC 4.0) 


\section{uss Ellibahá}

ISSN: 1984-6444 | http://dx.doi.org/10.5902/1984644443534

\section{Notas}

1 A reforma ministerial do governo de Jair Bolsonaro, em 2019, extinguiu o Ministério do Esporte sob a justificativa de enxugamento da máquina pública. Atualmente, o Programa Segundo Tempo está sob a responsabilidade da Secretaria Especial do Esporte atrelada ao Ministério da Cidadania. A decisão do governo de suplantar o caráter ministerial do esporte exige compreender as determinações sociais, políticas e econômicas. Segundo Frizzo (2019) o esporte foi relegado a segundo plano no aparato estatal sobe o ponto de vista administrativo por meio de ajustes fiscais que retiraram recursos de áreas sociais e incentivo à iniciativa privada para promoção de projetos e programas esportivos baseados em repasse de recursos públicos para empresas privadas.

${ }^{2}$ A pesquisa foi realizada com financiamento próprio e sob aprovação do Comitê de Ética da Pesquisa da Universidade Federal de Minas Gerais - Parecer consubstanciado n⒈325.659. Os dados e nomes da instituição e entrevistados foram preservados por meio do anonimato garantido nos termos de anuência da instituição e de consentimento e assentimento dos entrevistados. 